This item was submitted to Loughborough's Research Repository by the author.

Items in Figshare are protected by copyright, with all rights reserved, unless otherwise indicated.

\title{
Optimisation of machine components in thermal fusion bonding process of porous fibrous media: Material optimisation for improved product capacity and energy efficiency
}

\section{PLEASE CITE THE PUBLISHED VERSION}

http://dx.doi.org/10.1177/0954408914545195

\section{PUBLISHER}

(c) IMechE. Published by Sage.

\section{VERSION}

AM (Accepted Manuscript)

\section{PUBLISHER STATEMENT}

This work is made available according to the conditions of the Creative Commons Attribution-NonCommercialNoDerivatives 4.0 International (CC BY-NC-ND 4.0) licence. Full details of this licence are available at: https://creativecommons.org/licenses/by-nc-nd/4.0/

\section{LICENCE}

CC BY-NC-ND 4.0

\section{REPOSITORY RECORD}

Peksen, Murat, Memis Acar, and W. Malalasekera. 2019. "Optimisation of Machine Components in Thermal Fusion Bonding Process of Porous Fibrous Media: Material Optimisation for Improved Product Capacity and Energy Efficiency". figshare. https://hdl.handle.net/2134/25691. 


\title{
Optimisation of machine components in thermal fusion bonding process of porous fibrous media: Material optimisation for improved product capacity and energy efficiency
}

\author{
M Peksen, M Acar and W Malalasekera
}

\begin{abstract}
A comprehensive parametric study to aid in the material optimisation of the thermal fusion bonding machine components for improved product capacity and energy efficiency is introduced. The effect of conveyer belt and drum cover material type on the thermal bonding performance has been systematically investigated. A previously validated 2D computational fluid dynamics model based on the theory of porous media has been used for the study. The PEEK material is determined to be showing the greatest optimisation potential for higher production rates. The optimum material match for the highest production rates has been determined, considering the effect of material type on the thermal bonding time. Improved product quality associated with a uniform temperature distribution has been achieved by using PEEK material. The conveyer belt component has been determined as the highest energy-absorbing component and could be optimised.
\end{abstract}

Keywords: nonwoven, thermal bonding, porous media, CFD, computational optimisation, energy efficiency

\section{Introduction}

Nonwovens are a sheet, web or batt of natural or manmade fibres or filaments, excluding paper that have not been converted into yarns, but are bonded to each other by any of several means. ${ }^{1}$ For the present study, thermal fusion of the thermoplastic fibres through convective hot air is considered. A schematic of a typical thermal bonding machine is illustrated in Figure 1.

The thermal bonding machine has a perforatedrotating drum, a wire-mesh drum cover layer and a wire-mesh looped conveyor belt. The drum and drum cover are enclosed by a hood with an open section to enable the conveyor belt and the transported web to enter and exit the thermal bonding machine. The nonwoven web enters the machine transported by the conveyor belt, from room temperature, and is then subject to hot air flow, which is at or just above the melting temperature of the sheath fibre material. The web is located such that it is wrapped around the drum, sandwiched between the conveyor belt and the drum cover, first travelling through the machine's heating zone facilitating the bonding of the contacting fibres, and then it is briefly subject to a cool air flow before leaving the machine. ${ }^{2-4}$
The convective hot air flows through the conveyer belt, then through the porous nonwoven web and finally through the drum cover and the perforated drum (Figure 1). All these elements enter the heating zone at different but much lower temperatures than the air temperature, thus absorbing a significant amount of energy from the air. ${ }^{3}$ For details about the flow and heat transfer inside the machine together with experimental measurements, see Peksen et al. ${ }^{3}$

During the last years, the increasing demand on higher thermal bonding production rates and energy efficiency has motivated interest in optimising the thermal bonding machine settings. The optimization and level of improvement is dependent upon a thorough understanding of the thermofluid flow behaviour and the related parameters, affecting the process. A strategic optimisation approach combining measurements, design of experiments and computational techniques has been introduced by Peksen et al., 5,6 to optimise complex industrial processes. To employ such process models, it is essential to employ an experimentally validated model, in order to success- fully carry out the optimisation, and to evaluate whether output from the process models can be used or not. 


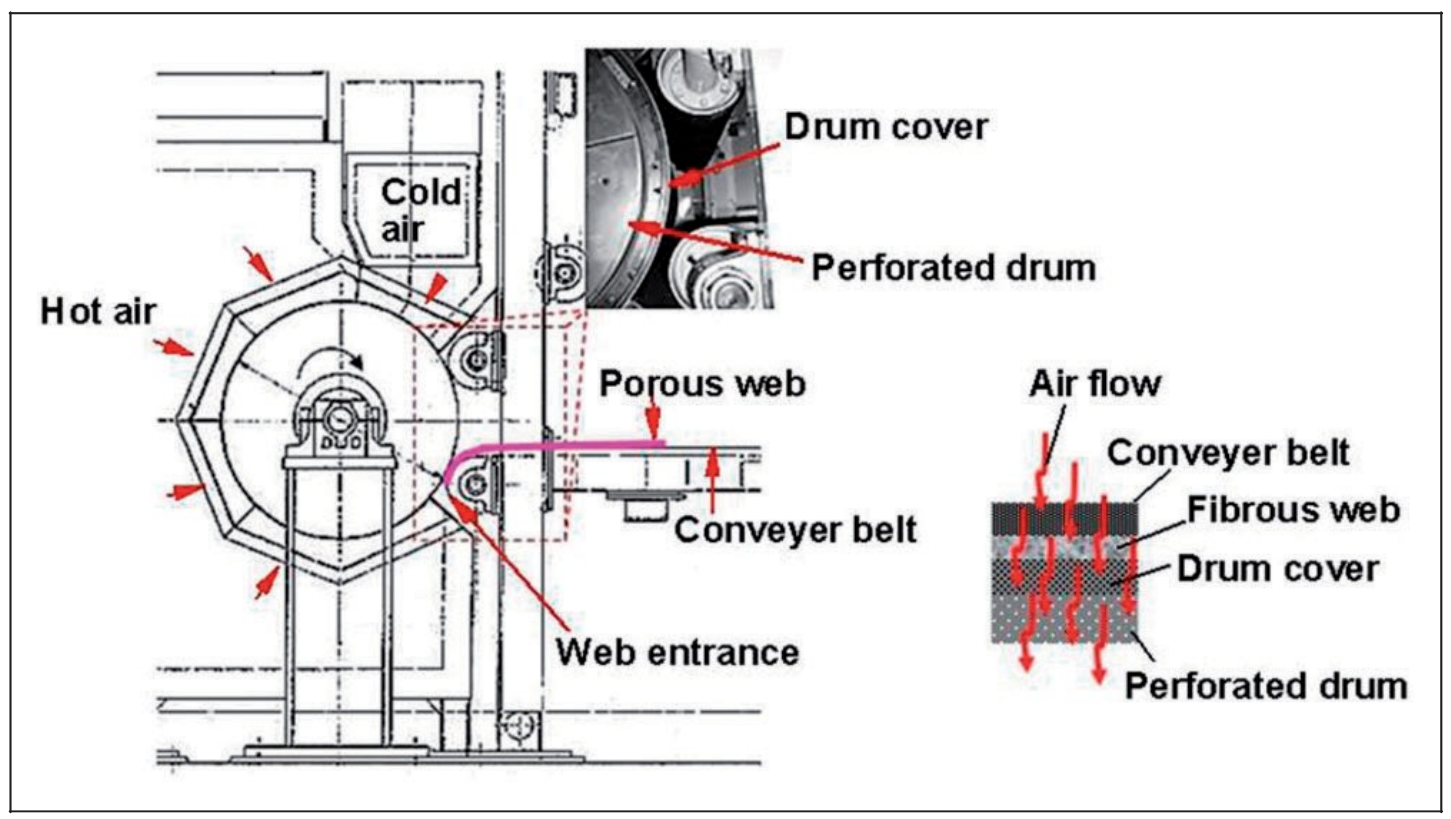

Figure 1. Schematic view of a typical thermal bonding machine and components.

In our previous studies, the thermal bonding process has been investigated using computational fluid dynamics (CFD). ${ }^{2-4,7-9}$ Process parameters have been systematically assessed and precise suggestions for improved production rates and energy efficiency could be given. ${ }^{4}$ The attempt using CFD for the optimisation of the thermal bonding process has shown significant benefit. In a further study, the melting process of the thermoplastic fibres during nonwoven web formation has been the focus. The fibres' geometrical information and constitutive equations describing the material behaviour were mathematically described and implemented within the CFD code FLUENT ${ }^{\circledR}$. Fibre thickness, sheath fraction and thermophysical proper- ties such as melting temperature, latent heat of fusion and the liquid fraction were successfully investigated, enabling the assessment of different fibre types and to determine the properties of the fabric. The thermal gradients inside the web were determined to be due to the combined convection and latent heat of fusion effect, which stores heat to melt the fibres. ${ }^{7}$ The focus of the current study has been to understand and improve the production rate and energy efficiency of the thermal bonding process by means of component optimisation. The pilot machine component facilities at COLBOND bv, the Netherlands, are used for the study. Currently, the effect of employing different conveyer belt and drum cover materials on the \% nonwoven production rate and quality together with component energy efficiency is depicted. The optimisation goal is a cost-efficient approach. Thus, the developed, experimentally validated 2D model from our previous study has been used to aid in the industrial component optimisation procedure. $^{2}$
Materials used for the present study include the steel, aluminium and polyetheretherketon (PEEK). The most beneficial material combination for the conveyer belt and drum cover, resulting in the highest nonwoven production rate and component energy savings has been elucidated. The thermal gradients indicating the nonwoven product quality are predicted.

\section{Methodology}

To systematically study the effect of the component material type on the thermal fusion bonding performance, CFD is intensively employed. The previously proposed experimentally validated 2D CFD model ${ }^{3}$ based on the continuum theory of porous media is used. For details about the governing equations and the derivation of the flow properties together with the effective material properties, see Peksen et al. $^{3}$

The computational model as to give a brief review is modelled such that four layers, representing the system components lay on top of one another. The model comprises four cell zones (each representing one system layer) and 16 face zones. The cell zones are presented as porous fluid zones, allowing the air to flow through each model layer. The transient problem considers an approach in which a $5^{\circ}$ radial sector of the geometry has been used. Periodic boundary conditions are utilised. The model is subjected to thermofluid flow for a period of $22.4 \mathrm{~s}$ that corresponds to the dwell time of $236^{\circ}$ segment of the machine in the heating zone. A structured computational mesh of 8241 nodes is employed. The commercial code FLUENT $^{\circledR}$ has been used for the analyses. Figure 2 illustrates the used model. 


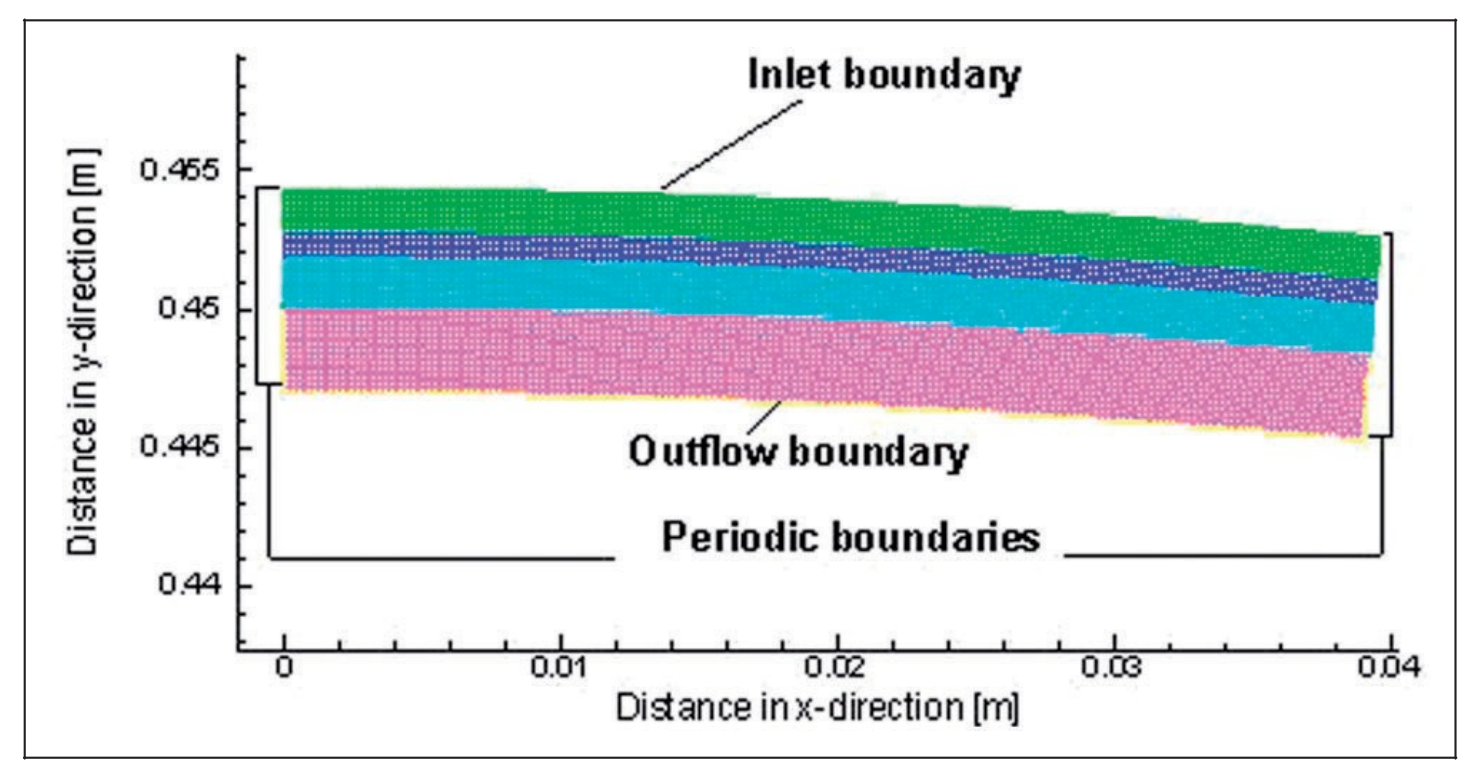

Figure 2. Employed computational fluid dynamics model. ${ }^{3}$

The basic CFD configuration simulates the validated model for a $200 \mathrm{~g} / \mathrm{m}^{2}$ nonwoven fabric with an experimentally determined air inlet velocity of $0.665 \mathrm{~m} / \mathrm{s}$ and an air temperature of 225 ${ }^{\circ} \mathrm{C}$. The web was assumed to be made of sheathcore type bi-component fibres of nylon (polyamide) 6 (PA6) sheath and polyester (PET) core with a nonwoven thickness of $0.909 \mathrm{~mm}$, corresponding to $200 \mathrm{~g} / \mathrm{m}^{2}$. The melting point of the nylon sheath was experimentally determined as $221{ }^{\circ} \mathrm{C}$. The conveyor belt speed was $5 \mathrm{~m} /$ min.Porosities for the nonwoven, conveyer belt and the drum cover are considered to be as 0.88 , 0.43 , and 0.70 , respectively. The basic configuration uses steel for both the conveyer belt and the drum cover material. The drum material is also made of steel and will be kept constant throughout the study. The introduced data have been taken from Peksen et al. ${ }^{3}$ Results obtained from these parametric studies will enable to identify the most beneficial machine component material combination. The used material types, i.e. aluminium, PEEK and steel are feasible materials suggested by the industrial partner Colbond bv. The effective thermophysical properties are determined based on the standard bulk material properties.

\section{Results and discussion}

In this section, the effect of the conveyer belt and drum cover material type on the thermal fusion bonding process is presented. The materials selected for the conveyer belt and the drum cover are matched combinations of steel, PEEK and aluminium, which are illustrated in Table 1 . The combination St-St presented as CFD Run 1 is the baseline configuration used for comparison purposes and it is the current material combination used in the analysed machine. All possible combinations are investigated.

CFD analyses were performed and the results for optimising the production rates, product quality and energy efficiency are depicted. Process conditions are kept the same as used for the baseline simulations, i.e. an air temperature of $225^{\circ} \mathrm{C}$ and an air inlet velocity of $0.665 \mathrm{~m} / \mathrm{s}$.

\section{Aluminium belt-aluminium drum cover}

The analyses presented for this section cover the comparison of the baseline CFD analyses for the current process, considering the conveyer belt and drum cover material as steel, and the CFD predictions performed for the optimised configuration of the belt and drum cover made of aluminium. Figure 3 illustrates the results.

Table I. Material combinations used for the CFD analyses.

\begin{tabular}{ll}
\hline CFD Run & $\begin{array}{l}\text { Material Belt/ } \\
\text { Drum cover }\end{array}$ \\
\hline 1 & St-St \\
2 & AL-AL \\
3 & AL-PEEK \\
4 & AL-St \\
5 & PEEK-AL \\
6 & PEEK-PEEK \\
7 & PEEK-St \\
8 & St-AL \\
9 & St-PEEK \\
\hline
\end{tabular}

The results for the temperature distribution show that it is possible to reduce the bonding time of the nonwoven fabric. However, the temperature differences within the fabric show that the web mechanical properties will not be improved under the applied process conditions, despite having changed the material type of the machine component materials. The improvement of the temperature distribution over time is due to the material change. The increase in thermal conductivity and specific heat capacity of the used materials compared to steel led to increased heat transfer rates. 


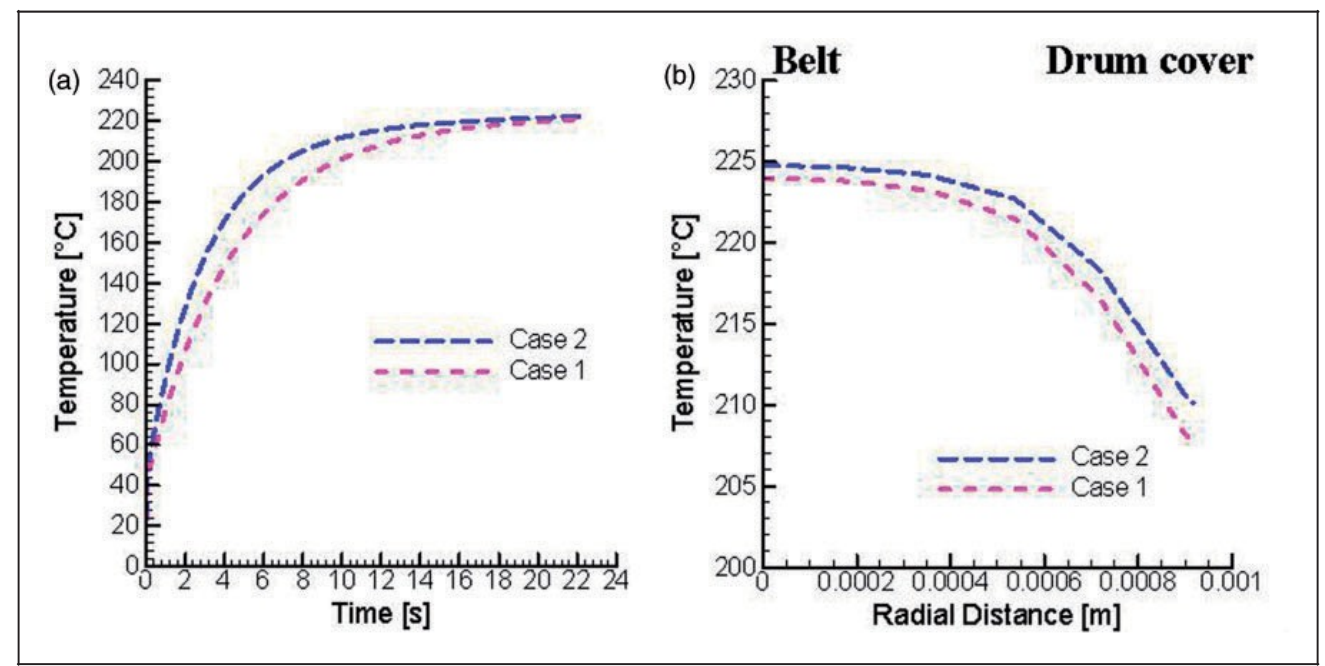

Figure 3. Comparison of current process and optimised process conditions. (a) Fabric temperature distribution and (b) temperature distribution within the fabric.
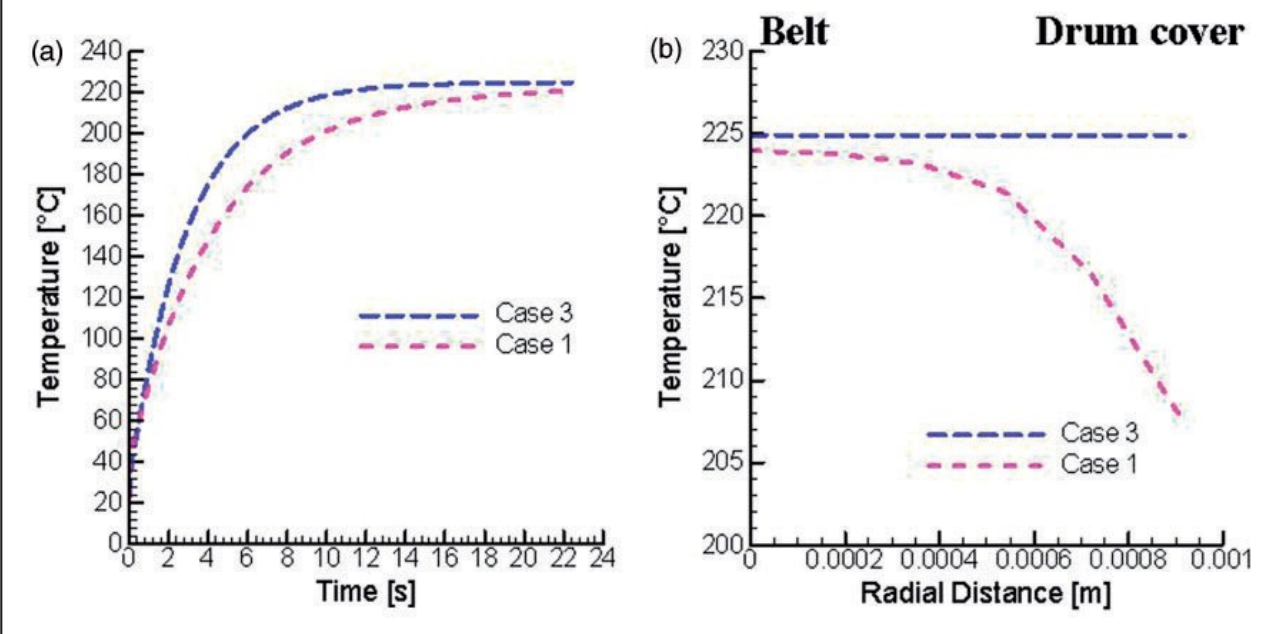

Figure 4. Comparison of current process and optimised process conditions. (a) Fabric temperature distribution and (b) temperature distribution within the fabric.

\section{Aluminium belt-PEEK drum cover}

The simulations consider the belt material as being made of aluminium, and the drum cover made of PEEK. The simulation results for the thermal behaviour of the nonwoven fabric are illustrated in Figure 4.

The results show a similar behaviour as for the previous optimising process. An improvement of the bonding time was achieved by reaching higher non- woven temperatures early in the process. A product optimisation was also achieved due to the removed temperature gradient within the nonwoven fabric. The temperature is uniform across the fabric; hence better mechanical properties of the web would be expected.

\section{Aluminium belt-steel drum cover}

The following CFD results present the thermal behaviour of the nonwoven fabric, which was performed considering the belt as made of aluminium and the drum cover material made of steel. Figure 5 illustrates the temperature distribution of the fabric over time and thermal gradient within the nonwoven fabric.

The predicted results show that despite some improvement in the process, an improvement in product quality could not be achieved due to the thermal gradient retaining in both cases. 

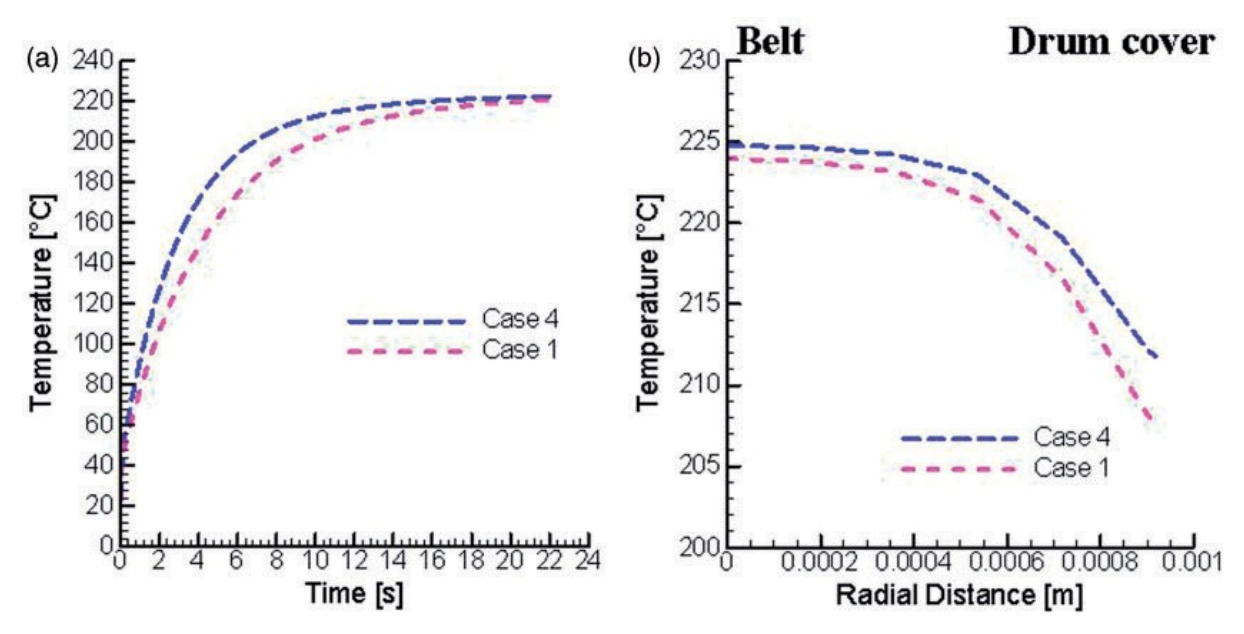

Figure 5. Comparison of current process and optimised process conditions. (a) Fabric temperature distribution and (b) temperature distribution within the fabric.
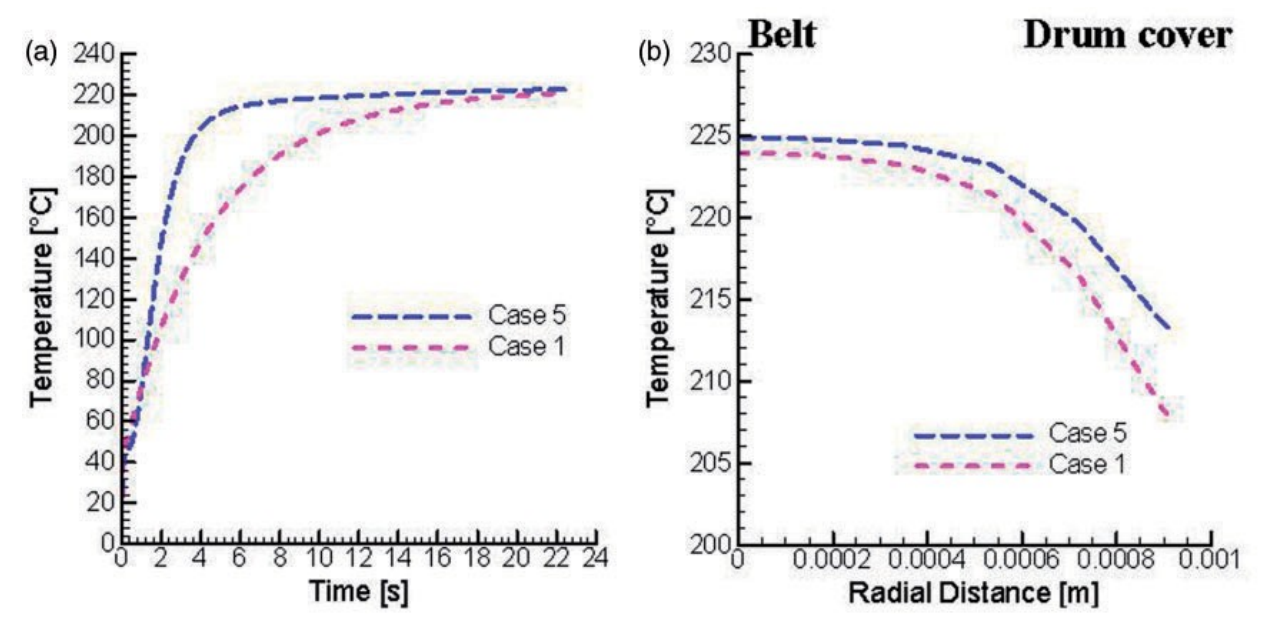

Figure 6. Comparison of current process and optimised process conditions. (a) Fabric temperature distribution and (b) temperature distribution within the fabric.

\section{PEEK belt-aluminium drum cover}

Figure 6 shows the CFD analyses for the PEEK belt-aluminium drum cover configuration. The temperature distribution of the nonwoven fabric is presented. Results show that the bonding time was reduced more by showing a sharper rise in the temperature distribution and achieving higher bonding temperatures, whereas the temperature gradient within the nonwoven fabric is retained. This suggests that the product properties would remain without being optimised.

\section{PEEK belt-PEEK drum cover}

The CFD results predicted for the PEEK belt-PEEK drum cover configuration are presented in Figure 7. Results reveal that due to the reduced bonding time, a significant improvement of production rates can be achieved. Furthermore, with the proposed material configuration, an improvement of the product properties could be obtained, due to the improvement of the thermal gradients within the nonwoven fabric. It is notice- able that an improvement in the process is predicted for configurations using PEEK as drum cover material, which should be reflected in the product properties. 

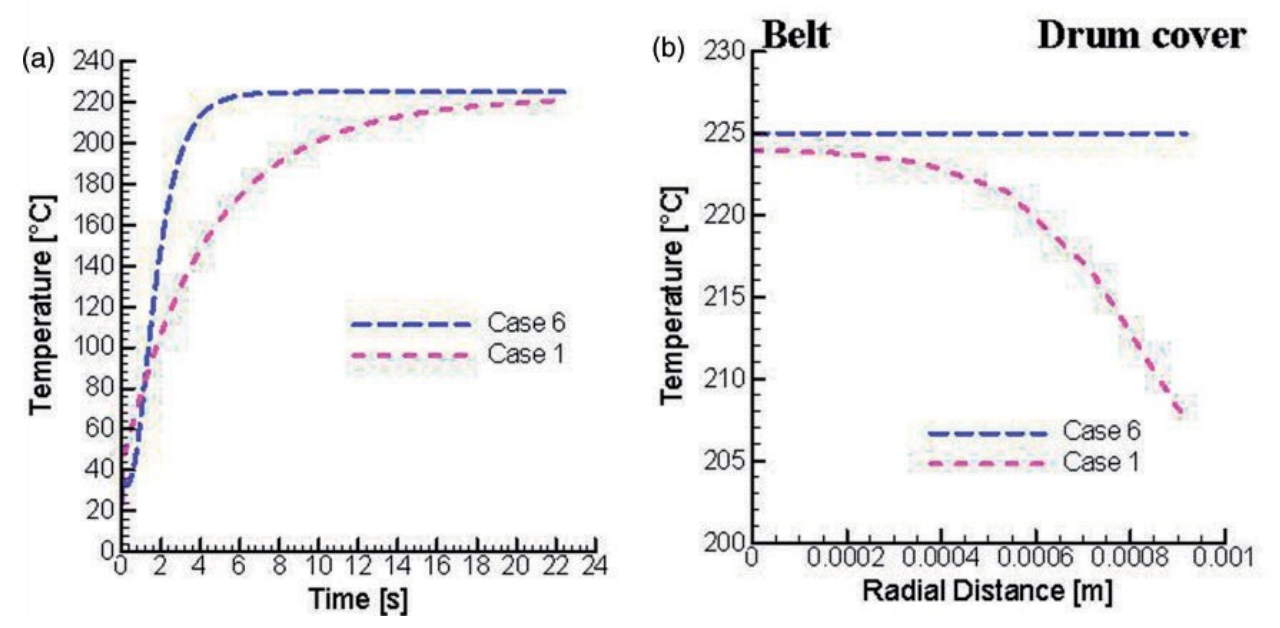

Figure 7. Comparison of current process and optimised process conditions. (a) Fabric temperature distribution and (b) temperature distribution within the fabric.

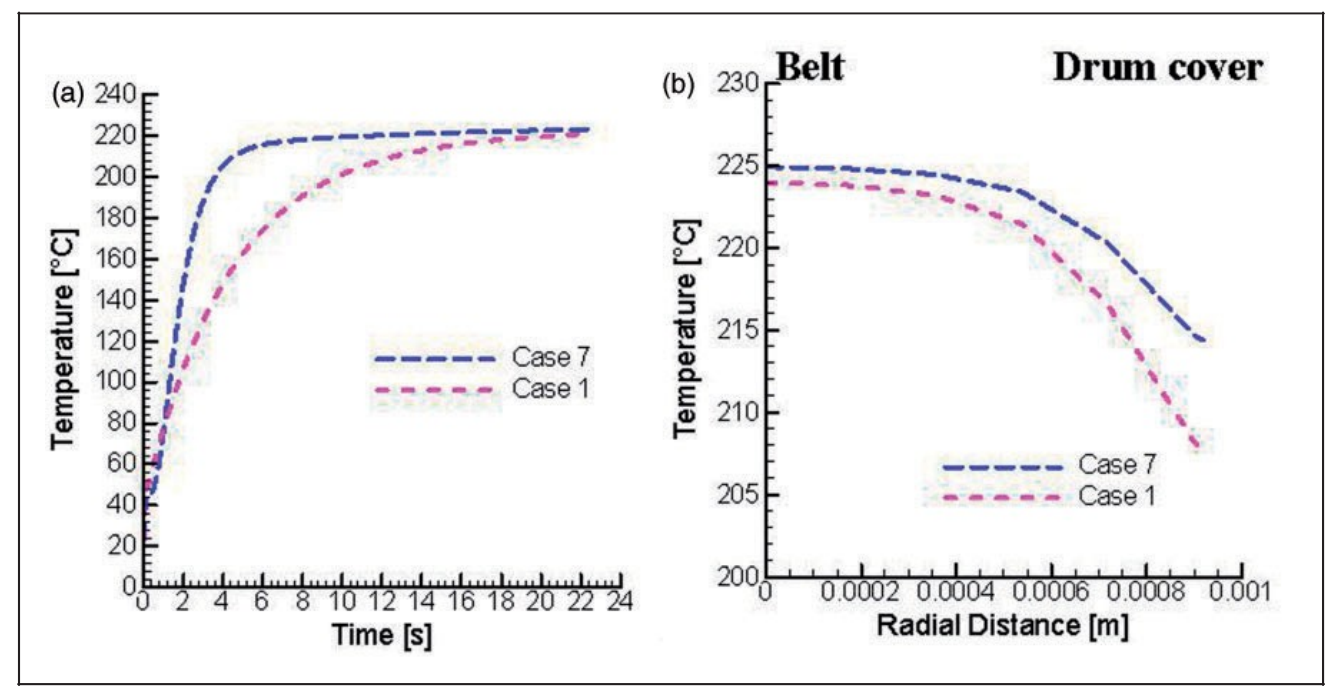

Figure 8. Comparison of current process and optimised process conditions. (a) Fabric temperature distribution and (b) temperature distribution within the fabric.

\section{PEEK belt-steel drum cover}

Figure 8 shows the simulated results for the PEEK belt-steel drum cover configuration. Results reveal that increased production rates are enabled using this configuration; however, it is visible that using the steel configuration for the drum cover retains the thermal gradient within the nonwoven fabric. This suggests that an improvement in product quality cannot be achieved with this type of configuration by keeping the remaining process conditions constant and only changing the material type of the components.

\section{Steel belt-aluminium drum cover}

Figure 9 shows the results of the CFD analyses for the steel belt-aluminium drum cover configuration. It is seen that the temperature distribution for the nonwoven shows a similar distribution; however, a slight increase in the thermal gradient within the nonwoven is present.
This suggests that the use of aluminium as drum cover material does not improve the process

conditions. The product quality should be similar to that of the baseline process (Case 1), considering the thermal behaviour of the nonwoven fabric.

\section{Steel belt-PEEK drum cover}

Figure 10 gives the results for the steel belt-PEEK drum cover configuration

The predicted results show a slight improvement of the temperature distribution over time, but a considerable improvement in the web temperature uniformity.

In general, when comparing the materials used for the processes, it is noticeable that in all cases where PEEK is used as drum cover material, an improvement of the thermal gradient within the nonwoven fabric is achieved. The use of aluminium for the drum cover does not make any significant improvement. 


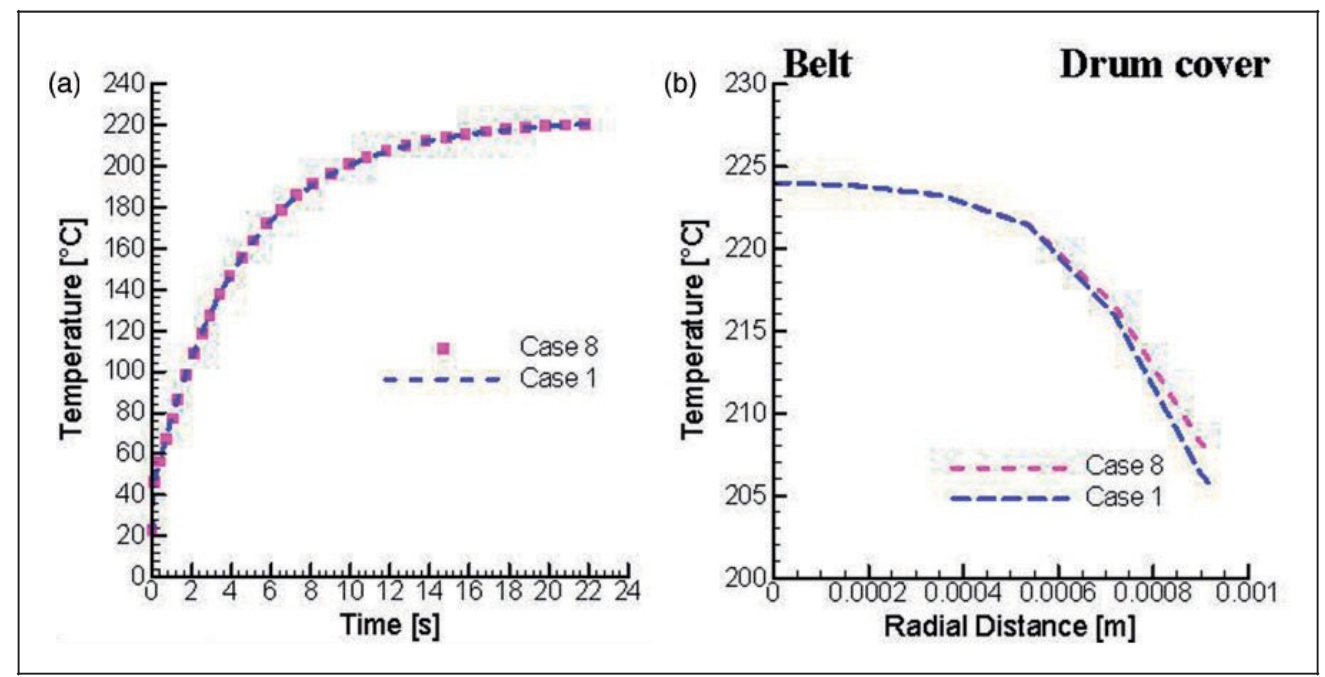

Figure 9. Comparison of current process and optimised process conditions. (a) Fabric temperature distribution and (b) temperature distribution within the fabric.

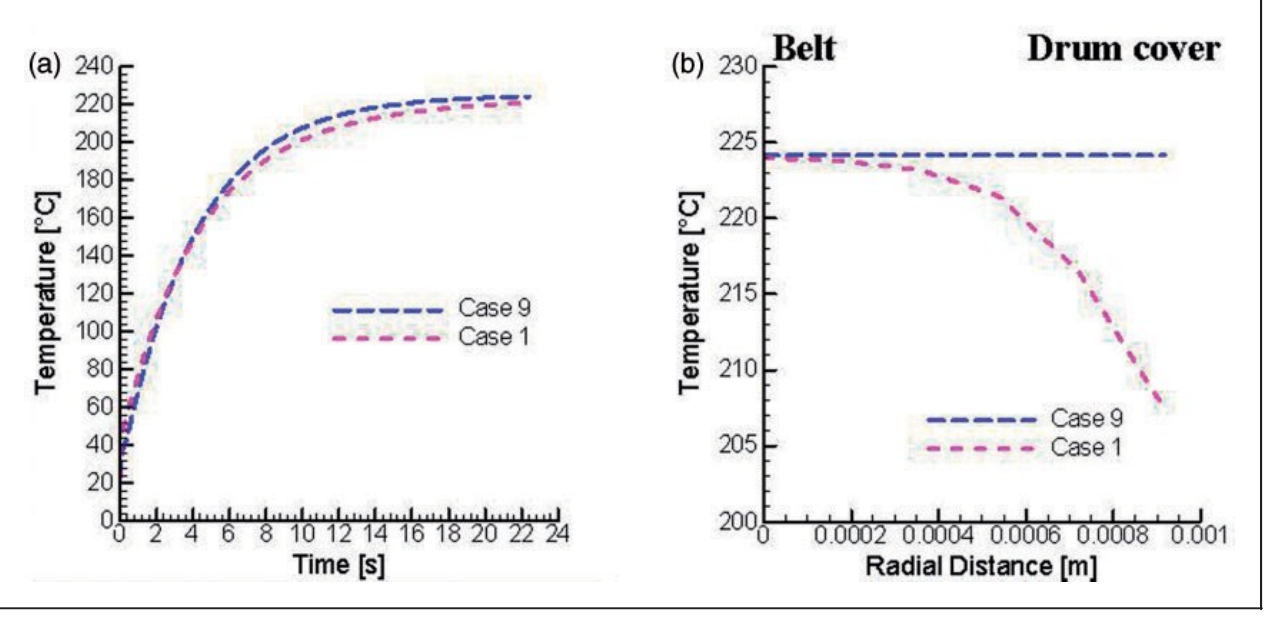

Figure 10. Comparison of current process and optimised process conditions. (a) Fabric temperature distribution and (b) temperature distribution within the fabric.

This is very clearly demonstrated for the case where only a material change in the drum cover was attended using aluminium (Figure 9). The temperature distribution shows very similar behaviour to the baseline results (Case 1), whereas even a slight thermal gradient within the nonwoven was observed.

An important outcome of the investigation is the improvement of the bonding time of the nonwoven fabric when both aluminium and PEEK are used as the belt material. This improvement is much higher for PEEK compared to the aluminium. This is attributed to the higher specific heat capacity of the PEEK material compared to steel and aluminium. In order to raise the temperature of a material, energy has to be supplied to it.

The addition of a given amount of energy does not always result in the same rise in temperature. The temperature of the material depends not only on the amount of energy supplied to it, but also on its size and nature. In order to compare the ability of the used different materials to absorb energy, the specific heat capacity is an important parameter. From its definition, i.e. the amount of heat required to change the temperature of $1 \mathrm{~kg}$ of a substance by 1 $\mathrm{K}$, it is obvious that the drum cover with higher specific heat capacity (PEEK) gains more heat and thus achieves higher temperatures.

This increases the temperature of the drum cover side of the nonwoven, hence reducing the thermal gradient within the web. To investigate the effect of the machine component material type on the non- woven production rates and energy efficiency, the optimum point of the analyses is determined. For this purpose, the bonding time and the percentage increase in total energy absorption of the nonwoven web compared to the baseline simulation are investigated. 


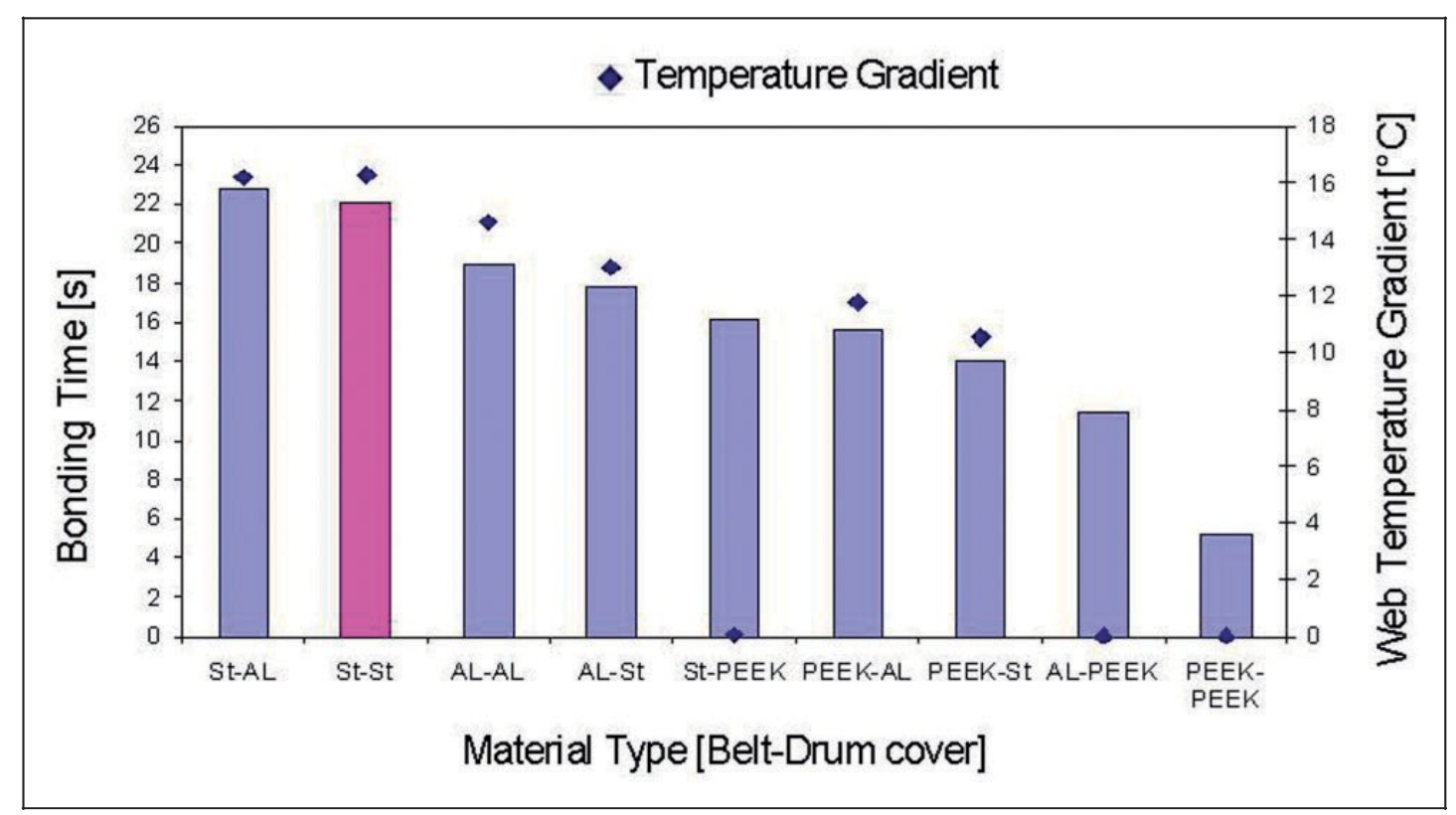

Figure 11. Optimisation of the thermal fusion bonding process for higher production rates and reduced nonwoven thermal gradients, using different machine component materials.

In order to evaluate and determine the most favourable material combination for the conveyer belt and drum cover, the results are plotted in a ranked order, according to the bonding time. Due to the low differences of the determined percentage increase in the web energy absorption (maximum $\mathrm{b} 4.6 \%$ when using Al-PEEK), attention is given to the production rate that is associated with the thermal fusion bonding time. Figure 11 illustrates the results. The basic configuration made of St-St is coloured in magenta.

The lowest bonding time, which enables the highest production rates, is achieved at run number six. This refers to the CFD configuration where PEEK is used as material for both the conveyer belt and the drum cover components. In general, the analyses reveal that the use of PEEK as drum cover enables a significant improvement of the thermal gradient inside the non- woven fabric, whereas the use of aluminium does not give any significant improvement.

It is noticeable that the use of PEEK as conveyer belt material leads to a significant reduction in thermal fusion bonding time, whereas the impact of improvement is low when aluminium is chosen. It is important to acknowledge that the material choice is upon whether the production rate and quality is more important, or the energy efficiency has a higher impact for the producer. To account for the overall machine energy efficiency, the calculation of the heat content is exceedingly important. The numerical calculations from the basic configuration where steel is used pro- vide information about the energy consumption of the whole thermal bonding system components, which is important for the optimisation of the process and the design of machine components.

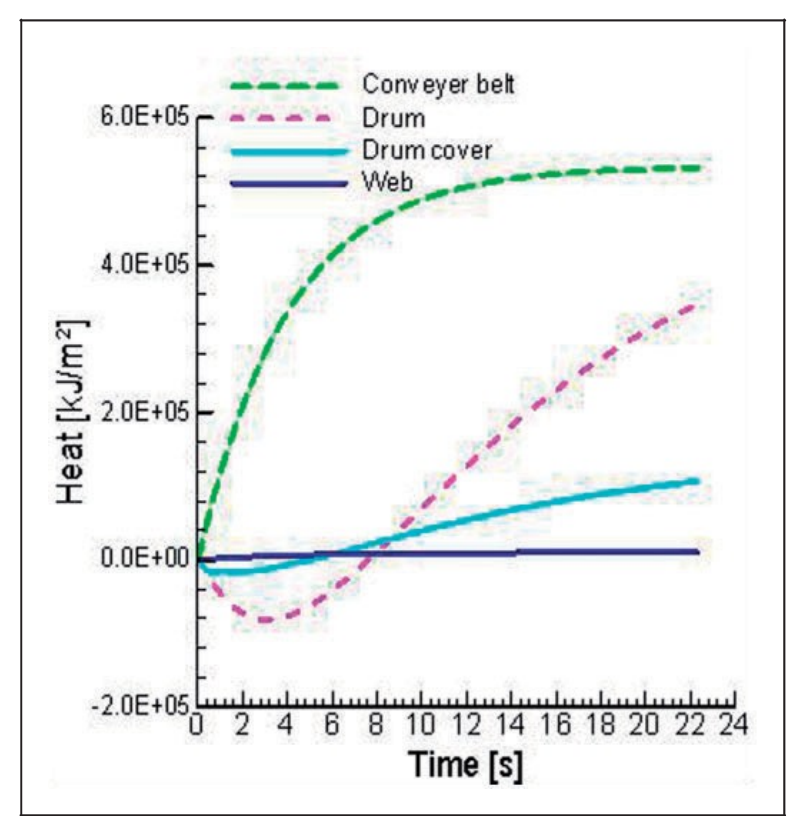

Figure 12. Heat consumption of the thermal fusion bonding machine components.

Figure 12 illustrates the heat content per unit area of the system. Relative values are used based on the $5^{\circ}$ model sector. Because of the large range values the data covers, the values are presented as exponents.

The results of the simulations show that there is a great difference of the heat content distribution within the thermal fusion bonding system. It is clear that the conveyer belt component absorbs the highest amount of heat, whereas the nonwoven fabric achieves the lowest rates. This is due to the enthalpy differences of the system components associated with the mass of each of the layers. The belt with the low temperature $\left(30^{\circ} \mathrm{C}\right)$ needs a high amount of energy to be heated up, compared to the drum cover and drum which have much higher initial temperatures $\left(145^{\circ} \mathrm{C}\right)$. 


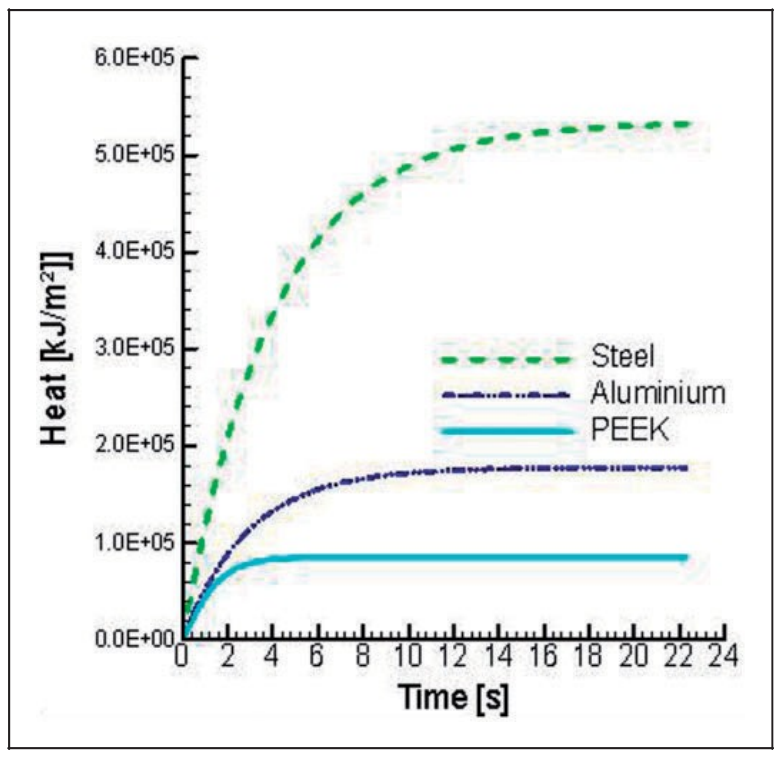

Figure 13. Heat consumption analysis of the conveyor belt component.

The drum with its higher mass needs longer time to be heated up further, thus the drop in temperature in the first $3 \mathrm{~s}$. As it is visible from Figure 12, the conveyer belt has the greatest impact on the energy consumption within the system. Due to this result, the heat consumption of the belt material is investigated for potential component material optimisation. PEEK and aluminium material which are used in the parametric study are used to simulate the heat consumption of the conveyer belt component. The results are illustrated in Figure 13.

The results show the absorbed heat content differences between steel, PEEK and aluminium belt. It is obvious that in terms of energy efficiency, the steel conveyer belt material also has a negative effect on the heat consumption, thus on the energy efficiency. When aluminium is used as the belt material, the amount of consumed heat reduces to one-third of the amount absorbed by the steel belt. The value decreases even to one-sixth of the amount when PEEK is used.

The differences are due to the low density materials used in the analysis, which leads to lower mass, thus decreasing the total amount of heat required to increase the temperature of the materials (Table 2). Accordingly, for energy savings the use of PEEK is also beneficial.

\section{Conclusions}

In this paper, the optimisation opportunities provided by the CFD technique were used to perform a comprehensive parametric study to aid in the optimisation of the thermal bonding process performed on the pilot machine at COLBOND bv, the Netherlands.
Table 2. Relative mass of the belt component used in the simulation.

\begin{tabular}{lc}
\hline & Mass $[\mathrm{kg}]$ \\
\hline Steel Belt & 2628 \\
PEEK Belt & 448 \\
Aluminium Belt & 916 \\
\hline
\end{tabular}

An experimentally validated 2D continuum model based on the porous media concept was used to study the effects of three material types, namely PEEK, steel and aluminium on the nonwoven production rate and thermal gradients. Results revealed that the use of PEEK material both for the conveyer belt and the drum cover results in the highest production rates as well as a uniform temperature distribution inside the nonwoven web layer, which would improve the web properties. Furthermore, the conveyer belt is determined to be the machine component consuming the highest amount of energy, which could also be reduced by employing low-density materials like the tested PEEK. This is attributed to the lower mass, decreasing the total amount of heat required to increase the temperature of the materials. Aluminium material reduces the energy consumption as well. However, the improvement in nonwoven production rates and product quality associated with thermal gradients deviate not significantly from the default use of steel component when it is used as a drum cover material. Air velocity has the greatest effect on the bonding time; thus, for higher production rates, the increase in air inlet velocity would be of advantage. Thisindicates ahigher conveyor belt speed capability. As an alternative, the use of a conveyor belt with higher porosity rates would lead to higher production rates. The CFD model is an invaluable tool to improve the knowledge early in the process and prior costly component design changes are performed.

\section{Funding}

We gratefully acknowledge the financial and technical support provided by COLBOND bv, The Netherlands, for this research.

\section{Conflict of interest}

None declared.

\section{References}

1. Butler I. Nonwoven fabrics handbook. Cary, NC: INDA, 1999.

2. Peksen M, Acar M and Malalasekera W. Computational modelling and experimental verification of through-air bonding nonwovens process. In: Proceedings of the international nonwovens technical conference, Atlanta, GA, USA, 24-27 September 2007. 
3. Peksen M, Acar $\mathrm{M}$ and Malalasekera W. Computational modelling and experimental validation of the thermal fusion bonding process in porous fibrous media Proc IMechE, Part E: J Process Mechanical Engineering, 2011; 225: 173-182.

4. Peksen M, Acar M and Malalasekera W. Optimisation of the thermal fusion bonding process in porous fibrous media for improved product capacity and energy efficiency. Proc IMechE, Part E: J Process Mechanical Engineering 2012; 226: 316323.

5. Peksen M, Peters R, Blum L, et al. Design and optimisation of SOFC system components using a trio approach: measurements, design of experiments, and3D computational fluid dynamics. J Electrochem Soc ECS Solid Oxide Fuel Cell 11 2009; 25: 1195-1200.
6. Peksen M, Blum L and Stolten D. Optimisation of a solid oxide fuel cell reformer using surrogate modelling, design of experiments and computational fluid dynamics. Int $J$ Hydrogen Energy 2012; 37: 12540-12547.

7. Peksen M, Acar M and Malalasekera W. Transient computational fluid dynamics modelling of the melting process in thermal bonding of porous fibrous media. Proc IMechE, Part E: J Process Mechanical Engineering 2013; 227: 254-263.

8. Hossain M, Acar M and Malalasekera W. A mathematical model for transverse airflow and heat transfer through fibrous webs. Proc IMechE, Part E: J Process Mechanical Engineering 2005; 219: 357-366.

9. Hossain M, Acar M and Malalasekera W. Modelling of the through-air bonding process. J Engineer Fibers Fabrics 2009; 4: 1-8. 